\title{
Novel Approach for Green Cloud Data Center Using IoT Sensor Device
}

\author{
Debabrata Sarddar ${ }^{1}$, Gourab Dutta ${ }^{2}$ and Rajat Pandit ${ }^{3}$ \\ ${ }^{1}$ Computer Science \& Engineering, University of Kalyani, Kalyani, Nadia, West Bengal, India \\ ${ }^{2}$ Computer Science \& Engineering, Brainware Group of Institutions, MAKAUT, Kolkata, India \\ ${ }^{3}$ Department of Computer Science, West Bengal State University, Kolkata, West Bengal, India \\ E-mail: gourabdutta15@gmail.com
}

\begin{abstract}
Cloud computing provides all the basic level of computing facility to complete the daily needs of a general or public community. In this paper, we concerned about the topic of carbon dioxide and carbon monoxide emission from cloud computing and its environmental effects and how to control it. Due to global warming and greenhouse effect, increasing the temperature of the environment day by day. In this paper, we concerned about how to control the problem of carbon dioxide and carbon monoxide emission from the cloud data center and also try to reduce the reaction cost. We use carbon dioxide and carbon monoxide measuring sensor Internet of Things (IoT) device and a chamber which contain solid sodium hydroxide at $130{ }^{\circ} \mathrm{C}$ and 6-8 bar pressure. We set one predefined threshold value into the IoT sensor and when the carbon dioxide and carbon monoxide increase then the value of IoT sensor also increase from predefined threshold value then only the chamber open automatically which contain solid sodium hydroxide at $130{ }^{\circ} \mathrm{C}$ and $6-8$ bar pressure. Then the reaction occur and produce sodium formate after the reaction with carbon monoxide and also produce sodium carbonate after the reaction with carbon dioxide. Again after the reaction when the IoT sensor value will decrease from predefined threshold value than the chamber automatically closed. In this way, we reduce the problem of carbon emission of the cloud data center and also reduce the reaction cost i.e. reaction occurs when needed. Keywords: Cloud Computing, Greenhouse gases, Environment Pollution, IoT sensors, Greenhouse Effect
\end{abstract}

\section{INTRODUCTION}

Cloud computing is an emerging technology of computer science and engineering. Cloud computing is helpful for moving data from the laptop, desktop, mobile to the larger cloud data center or the cloud environment. when data or information move from mobile, laptop or desktop to cloud data center then cloud data centers become over-sized. Then this types of cloud data centers will require huge power, aircooling system, expert manpower, and other resources and required infrastructure to maintain the cloud data center. The user only pays according to their requirement they don't pay for the cloud infrastructure this is the main advantage of cloud computing. Expert manpower maintenance and responsible for cloud infrastructure. But there are some major problems in cloud data centers like high deployment and energy consumption, operational cost, security-related problem, greenhouse gas emission, and environmental pollution.

But in this paper, we address the problem of the environmental pollution of cloud computing due to greenhouse gas emission from the cloud data center and try to reduce the carbon emission from cloud data center using some chemical reaction and using IOT sensors for reducing the cost. Cloud computing increasing the temperature of the whole world due to greenhouse gas emission from the data center. We mainly focus on carbon dioxide, carbon monoxide emission from the cloud data center. Due to the rise of the cloud data center, one important questions raised its environmental acceptable. Although when cloud computing has been considered widely in the research then the energy efficiency of the cloud data center as a whole has not been considered. Cloud computing also increase Internet traffic and expanding information database also increase the temperature of the environment and decrease energy savings. Thus, this paper discusses the environmental pollution control due to rapidly increase the cloud data center by analyzing various mechanism and technologies that support to reach this goal. Our research is important for the users and organization that are looking at Cloud computing as a solution for their, administrative, infrastructural and management problems. In this paper, we use solid sodium hydroxide or $\mathrm{NaOH}$ sodium hydroxide available in flakes, granules, and also 50\% saturated solution. Sodium hydroxide mainly ionic it containing hydroxide ions and sodium ions.

In Section II, related work is discussed. Section III is about the proposed work and how to control the greenhouse gas in a cloud data center with the architecture and how to reduce the reaction cost. In the section, IV describe the simulation and result and in section, $\mathrm{V}$ shows the flow chart of the system. Section VI is all about the conclusion and future work.

\section{RELATED WORK}

In cloud computing, many devices used and by using those device user data reached to cloud data center. Due to the use of many electronics device the temperature and humidity of environment increase day by day. Due to this environment pollution agricultural industry also affected. Although the water vapor humidity control is the main cause for the growth of crops. Humidity may lean down due to the photosynthesis process which depends on the emission of $\mathrm{CO}_{2}$ [1]. Soil control also responsible for the growth of the crop. The fertilization and irrigation of the crop depend on 
phase, type, and climate of the environment. Moisture, $\mathrm{pH}$, the temperature of the environment are essential parameters to monitor the soil condition [2]. From cloud data center hydrogen, nitrogen, carbon dioxide, and carbon monoxide gas emission increase day by day. To control those greenhouse gas mainly carbon dioxide and carbon monoxide from the cloud data center we use solid sodium hydroxide at $130{ }^{\circ} \mathrm{C}$ and $6-8$ bar pressure at the end of the data center. After the emission of carbon dioxide and carbon monoxide produce sodium formate and sodium carbonate with the reaction of solid sodium hydroxide [3]. The greenhouse is the best option to control environmental pollution control. Although the greenhouse has some disadvantages like visual inspection hand-operated growth of the plant, temperature control, hand-operated spraying pesticide, and fertilizer. But it is more time consuming, less accurate, may be human error occur and it's also unreliable so the fully automated greenhouse is the best solution to overcome this problem [5]. The humidity and temperature of the cloud data center also control by using a cooling system. Cooling starts with the computer room air handler (CRAH), which transfer the heat from the cloud data center to the chilled water. For applying this method to extracting heat required huge energy. But by using this CRAH technique we can increase cloud environment thermal load and also can control the outside temperature [4]. Nowadays cloud data center becoming huge and require huge energy for maintaining the cloud data center due to this huge energy the $\mathrm{CO}, \mathrm{CO}_{2}$, and other greenhouse gas emissions from the cloud data center and this is the main source of environmental pollution. To control this problem many techniques are used like virtualization technique to get the optimal solution of energy consumption of cloud data center [7]. Although we can measure energy consumption in cloud data environment during different runtime tasks. We can also measure cloud system performance and reading of energy consumption through different proposed model and analysis tool [8]. The system collects different environmental parameters like humidity, ph of soil etc. inside the greenhouse tunnel. Those parameters which are collected from the environment by using network sensors and cloud IOT device which is called CloudIoT [6]. Smart Home applications of Internet of Things (IoT) device can use with Web Service and Cloud Computing environment and also we can write the application code for working of this IoT device into the web and cloud environment into the Arduino platform and for the network connection we use network smart things using Zigbee technology using cloud service [9]. For example, we can remotely access the home information into the mobile device. For smart home management, the system use domain-object hierarchical model for addressing the home context technically the system use Simple Object Access Protocol (SOAP) and Web Services Description Language (WSDL) for enabling the remote access of home information into the mobile devices [10].

The environmental parameter can control or monitor through a mobile phone. Actually, the mobile device connected with the central server which is connected to the microcontroller through serial communication. The microcontroller communicates a different type of environment parameter measuring sensor [11]. The energy consumption of the cloud data center estimated at $26 \mathrm{GW}$ corresponding to about $1.4 \%$ of energy consumption with the growth rate $12 \%$ per year $[13,[14]$. The Barcelona medium-size Supercomputing Center (a data center) annual energy consumption of $1.2 \mathrm{MV}$ and pay near about $£ 1$ million amount for its energy consumption [15], i.e the required power is equivalent to the power of 1,200 houses [16]. A new power based scheduling algorithm [12] use for minimum power consumption where the virtual machine utilization is optimal by using the technique virtual machine can design, migration and dynamic shutdown can be managed according to the requirement, in this way by using this technique we can save the energy of cloud data center, as well as the operational cost of cloud data center, can reduce.

\section{PROPOSED WORK}

Due to established more cloud data center the greenhouse gas emission increase rapidly. In this paper we discuss some problems like emission of greenhouse gas mainly carbon monoxide, carbon dioxide has been addressed and try to reduce these problems using some extended techniques and IoT sensor we also try to reduce the reaction cost. We use a sensor into the cloud data center for controlling Environment pollution. We set predefined threshold values of the sensor for measurement of the carbon monoxide and carbon dioxide emission from the cloud data center, depending on sensor readings we are going to control the carbon monoxide and carbon dioxide which emissions from the cloud data center. When the sensor value increase from the predefined threshold values then the chamber open where solid sodium hydroxide store at 6-8 bar pressure and the chamber temperature is $130^{\circ} \mathrm{C}$ [3]. Carbon monoxide which emissions from cloud data center than do the reaction with solid sodium hydroxide and produce sodium formate which is not harmful to the environment also the carbon dioxide does the reaction with solid sodium hydroxide and produce sodium carbonate which is also not harmful to the environment. After the reaction when the threshold values of the sensor reduce then the chamber automatically closed. In this way we can control the carbon monoxide and carbon dioxide emission from the cloud data center and also reduce the reaction cost i.e reaction occurs only when needed. Actually, we don't know when which gas will be emission from the cloud data center only when the sensor value increase from the threshold value then only the chamber open and reaction occurred with solid sodium hydroxide. Carbon monoxide and carbon dioxide are more harmful to the environment so we try to reduce the emission of those gases from the cloud data center. Among those gases carbon monoxide automatically convert into the sodium formate after the reaction with solid sodium hydroxide and carbon dioxide automatically convert into the sodium carbonate after the reaction with solid sodium hydroxide which is 
store into the chamber from before both are not harmful to the environment.

In this paper, we proposed a new model For reducing carbon monoxide and carbon dioxide by using a carbon dioxide and carbon monoxide measuring sensor and solid sodium hydroxide into the chamber at 6-8 bar pressure and the chamber temperature is $130^{\circ} \mathrm{C}$ [3]. When the sensor measuring value increase from the predefined threshold values then the chamber open and $\mathrm{NaOH}$ do the reaction with $\mathrm{CO}$ and after the reaction, it produces sodium formate. The equation is $\mathrm{NaOH}(\mathrm{s})+\mathrm{CO}(\mathrm{g}) \rightarrow \mathrm{HCO}_{2} \mathrm{Na}$ (s) ( Sodium Hydroxide + Carbon monoxide $=$ sodium formate ). Also, carbon dioxide does the reaction with solid sodium hydroxide and after the reaction, it produces Sodium carbonate and water. The equation is $2 \mathrm{NaOH}+$ $\mathrm{CO}_{2} \rightarrow \mathrm{Na}_{2} \mathrm{CO}_{3}+\mathrm{H}_{2} \mathrm{O}$ (Sodium Hydroxide + Carbon Dioxide $=$ Sodium carbonate + water $)$ [3]. Both are not harmful to the environment.

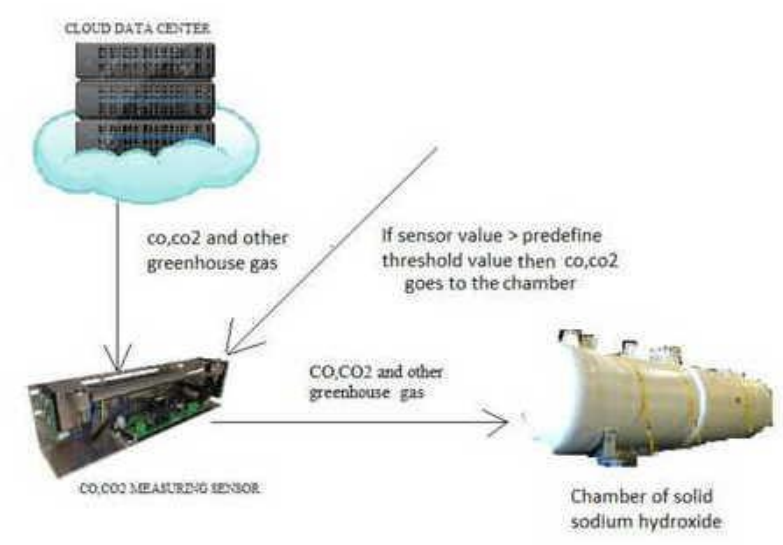

Fig. 1 Basic Block Diagram of our proposed model of cloud data center

\section{SIMULATION AND EQUATION}

Carbon dioxide, carbon monoxide and other greenhouse gas emissions from the cloud data center. We use an IoT sensor and set a predefined threshold value into this sensor. When the sensor value increase from predefined threshold value i.e $\mathrm{CO}$ and $\mathrm{CO}_{2}$ increase then the chamber open which contains the solid sodium hydroxide at 6-8 bar pressure and $130{ }^{\circ} \mathrm{C}$ before. When the chamber opens then the carbon monoxide does the reaction with $\mathrm{NaOH}$ and produce sodium formate. $\mathrm{NaOH}(\mathrm{s})+\mathrm{CO}(\mathrm{g}) \rightarrow \mathrm{HCO}_{2} \mathrm{Na}$ (s) (Sodium Hydroxide + Carbon monoxide = sodium formate). Also, $\mathrm{CO}_{2}$ does the reaction with $\mathrm{NaOH}$ and produce sodium carbonate. $2 \mathrm{NaOH}+\mathrm{CO}_{2} \rightarrow \mathrm{Na}_{2} \mathrm{CO}_{3}+\mathrm{H}_{2} \mathrm{O}$ (Sodium Hydroxide + Carbon Dioxide $=$ Sodium carbonate + water $)$ [3]. After the reaction when the $\mathrm{CO}$ and $\mathrm{CO}_{2}$ reduce then the predefined threshold value of sensor decrease then the chamber closed automatically. $\mathrm{CO}$ and $\mathrm{CO}_{2}$ increase day by day for the cloud computing data center. Nowadays the co is $11 \mathrm{mg} / \mathrm{m} 3$ and the co become $30 \mathrm{mg} / \mathrm{m} 3$ if the co increase in this way due to the cloud data center.

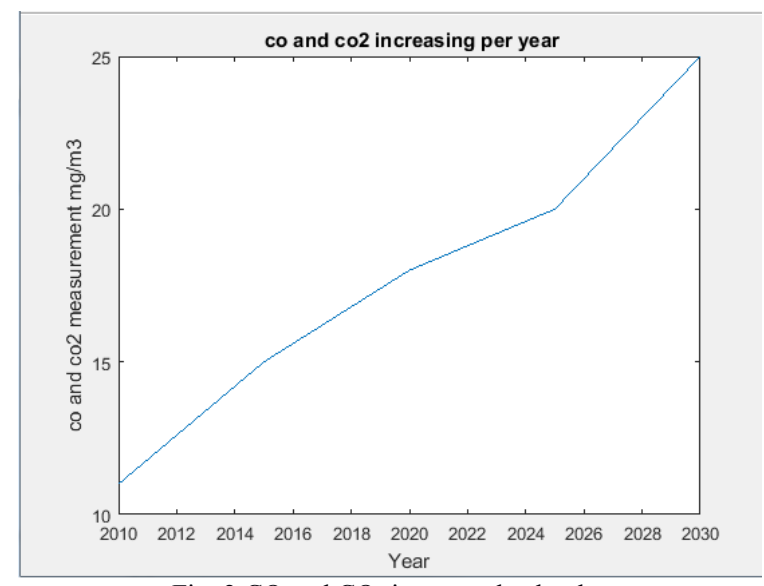

Fig. $2 \mathrm{CO}$ and $\mathrm{CO}_{2}$ increase day by day

But using our proposed model we can reduce the $\mathrm{CO}$ and $\mathrm{CO}_{2}$ due to the cloud data center. We can reduce and control the $\mathrm{CO}$ and $\mathrm{CO}_{2}$ and within the year $2030 \mathrm{CO}$ become 7 $\mathrm{mg} / \mathrm{m} 3$ by using our proposed cloud data center model.

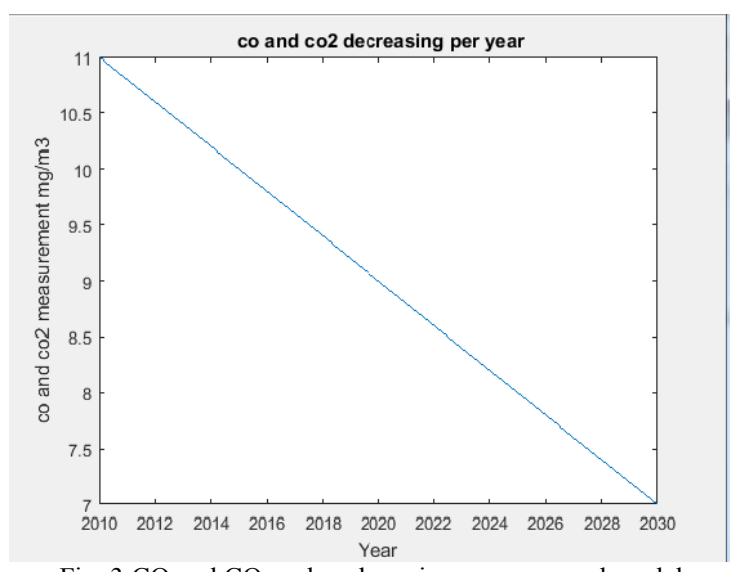

Fig. $3 \mathrm{CO}$ and $\mathrm{CO}_{2}$ reduce by using our proposed model

\section{FLOWCHART}

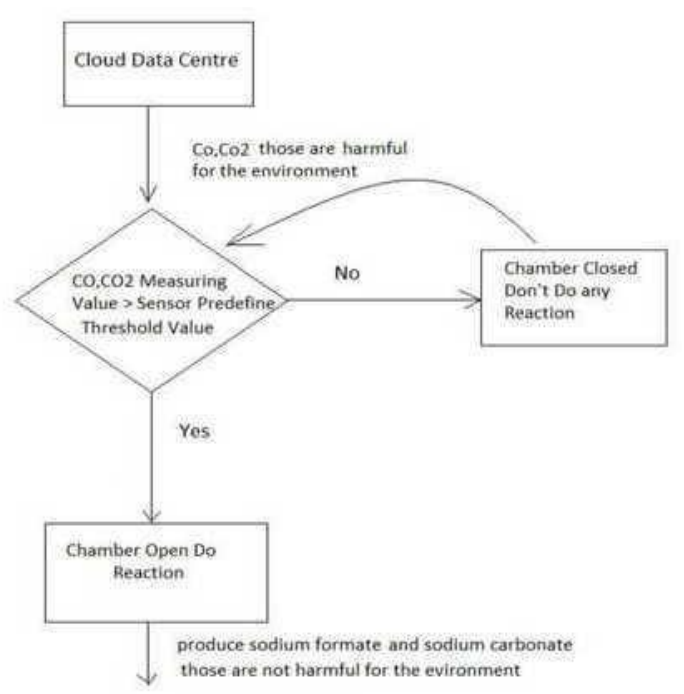

Fig. 4 Flow Chart of our proposed model of cloud data center 


\section{CONCLUSION AND FUTURE WORK}

Nowadays a day's environment pollution increase due to greenhouse effect or greenhouse gas emission from IT Industry mainly from the cloud data center. Due to the pollution temperature of the environment increase. In this paper, we mainly focus on environment pollution due to an increase in the cloud data center. We try to reduce carbon emission from the cloud data center using some extent model of cloud computing and IoT sensor. By using this new technique, we may be claimed environment as green and also try to reduce the reaction cost.

In the future, we try to reduce the heat consumption problem of cloud data center and also try to control the emission of other greenhouse gas like Nitrogen $(\mathrm{N})$ from cloud data center using any other external technique. Because the heating problem is another major problem in the cloud data center.

\section{REFERENCES}

[1] D. Chaudhary, S. P. Nayse, L. M. Waghmare, "Application of wireless sensor network for greenhouse parameter in precision agriculture", International Journal of Wireless \& Mobile Networks, Vol. 3, No. 1, pp. 140-149, Feb. 2011.

[2] R. Belsare, K. Deshmukh, M. Patil, Prof. Hattarge A.M., "Smart Greenhouse Automation", International Journal of Computer Science \& Engineering Technology, Vol. 5, No. 12, pp. 1127-1129, Dec. 2014.

[3] D. Sarddar, G. Dutta, R. Pandit, P. Sen, "A Proposed Model to Control the Environmental Pollution due to Carbon Emission from Cloud Data Center", International Journal of Research in Electronics and Computer Engineering, Vol. 7, No. 1, pp. 71-74, Jan-March. 2019.

[4] A. Uchechukwu, K. Li, Y. Shen, "Energy Consumption in Cloud Computing Data Centers", International Journal of Cloud Computing and Services Science, Vol. 3, No. 3, pp. 31-48, June 2014.

[5] S. D. Bhagwat, A. I. Hulloli, S. B. Patil, A. A. Khan, A. S. Kamble, "Smart Greenhouse using IOT and Cloud Computing", International Research Journal of Engineering and Technology, Vol. 5, No. 3, pp. 2330-2333, Mar. 2018.

[6] K. V. G. N. Kodandaramaiah, "Cloud IoT Based Greenhouse Monitoring System", Keerthi.v, Int. Journal of Engineering Research and Applications, Vol. 5, No. 10, pp. 35-41, Oct. 2015.

[7] M. Arif, T. Mahmood, "Cloud Computing and its Environmental Effects", International Journal of Grid Distribution Computing, Vol. 8, No. 1, pp. 279-286, 2015.

[8] F. Chen, J. Schneider, Y. Yang, J. Grundy and Q. He, "An energy consumption model and analysis tool for Cloud computing environments" 2012 First International Workshop on Green and Sustainable Software (GREENS), pp. 102-107, June 2012.

[9] M. Soliman, T. Abiodun, T. Hamouda, J. Zhou, C. H. Lung, "Smart Home: Integrating Internet of Things with Web Services and Cloud Computing", In Cloud Computing Technology and Science (CloudCom), 2013 IEEE 5th International Conference, Vol. 2, pp. 317-320, Dec. 2013.

[10] J.-Y. Son, et al., "Resource-aware smart home management system by constructing resource relation graph," IEEE Trans. On Consumer Electronics, vol. 57, No. 3, pp. 1112-1119, Aug. 2011.

[11] R. Belsare, K. Deshmukh, M. Patil, H. A. M., "Smart Greenhouse Automation" International Journal of Computer Science \& Engineering Technology, Vol. 5, No. 12, pp. 1127-1129, Dec. 2014.

[12] A. J. Younge, G. Laszewski, L. Wang, S. L. Alarcon, and W. Carithers, "Effcient Resource Management for Cloud Computing Environments," Proc. IEEE Int'l Green Computing Conf. (IGCC '10), pp. 357-364, Aug. 2010.

[13] BONE project, "WP 21 Tropical Project Green Optical Networks: Report on year 1 and unpdate plan for activities", No. FP7-ICT-20071216863 BONE project, Dec. 2009.

[14] J. Koomey, "Estimating Total Power Consumption by Server in the U.S and the World", Lawrence Berkeley National Laboratory, Stanford University, pp. 1-31, 2007.

[15] J. Toress, "Green Computing, The next wave in computing", Jordi Torres, In Ed. UPC Technical University of Catalonia, Barcelona, 2010.

[16] P. Kogge, “The Tops in Flops", pp. 49-54, IEEE Spectrum, Feb. 2011. 